\title{
Congenital and neonatal lupus erythematosus: two case reports
}

\author{
Lúpus eritematoso congênito e neonatal: relato de dois casos
}

\author{
Marcos Noronha Frey ${ }^{1}$ \\ Gabriela Czarnobay Garbin ${ }^{2}$ \\ Ana Elisa Kiszewski Bau ${ }^{4}$
}

\author{
Ana Elisa Empinotti Ioppi ${ }^{1}$ \\ Roque Domingos Furian ${ }^{3}$
}

\begin{abstract}
Neonatal lupus erythematosus is an autoimmune disease produced by the passage of maternal antinuclear antibodies and extractable nuclear antigen antibodies through the placenta. At the moment of the diagnosis, the mothers are asymptomatic in 40 to $60 \%$ of cases. The most common manifestations are cutaneous lesions and congenital heart block. The cutaneous findings are variable and usually begin within the first weeks or months of life. Congenital lupus erythematosus is a congenital variant of neonatal lupus erythematosus. We present one case of congenital lupus erythematosus and one case of neonatal lupus erythematous, showing the variability of this disease.

Keywords: Congenital, hereditary, and neonatal diseases and abnormalities; Infant, newborn; Lupus erythematosus, cutaneous

Resumo: Lúpus eritematoso neonatal é uma doença auto-imune produzida pela passagem de anticorpos maternos antinucleares e anticorpos contra antígenos extraíveis nucleares através da placenta. No momento do diagnóstico, as mães são assintomáticas em 40 a $60 \%$ dos casos. As manifestações mais comuns são lesões cutâneas e bloqueio cardíaco congênito. Os achados cutâneos são variáveis e geralmente começam nas primeiras semanas ou meses de vida. Lúpus eritematoso congênito é uma variante do lúpus eritematoso neonatal. Apresentaremos um caso de lúpus eritematoso congênito e um caso de lúpus eritematoso neonatal, mostrando a variabilidade da doença.

Palavras-chave: Doenças congênitas, hereditárias e neonatais e anormalidades; Lupus eritematoso cutâneo; Recém-nascido
\end{abstract}

\section{INTRODUCTION}

Neonatal lupus erythematosus (NLE) is an uncommon disease, frequently undiagnosed, produced by the passage of maternal antinuclear antibodies (ANA) and extractable nuclear antigens (ENA) antibodies through the placenta. ${ }^{1}$ The ENA most important in the pathogenesis of disease are anti-Ro/SSA, anti$\mathrm{La} / \mathrm{SSB}$, and less frequently anti-RNP. At the moment of diagnosis, the mothers can be asymptomatic.
Cutaneous presentation is variable, but in most cases presenting as erythematosus scaling, typically an annular erythematous rash, and usually begins within the first weeks or months of life. ${ }^{1,2}$ We present one case of congenital lupus erythematous (CLE) and one case of NLE, with clinical and laboratorial differences, showing the variability of this disease.

\footnotetext{
Received on 12.07.2011.

Approved by the Advisory Board and accepted for publication on 30.08.2011

* Study carried out at the Dermatology Service of the Federal University of Health Sciences (Universidade Federal de Ciências da Saúde de Porto Alegre UFCSPA) and Pediatric Dermatology Outpatient Clinic of the Children's Hospital Santo Antônio - Charity Hospital of Porto Alegre (Hospital da Criança Santo Antônio - Complexo Hospitalar da Santa Casa de Misericórdia de Porto Alegre) - Porto Alegre (RS), Brazil.

Conflict of interest: None

Financial funding: None

Dermatologist - Dermatology Service of the Federal University of Health Sciences (Universidade Federal de Ciências da Saúde de Porto Alegre - UFCSPA) Porto Alegre (RS), Brazil.

Physician graduated from the Federal University of Health Sciences (Universidade Federal de Ciências da Saúde de Porto Alegre - UFCSPA) - Porto Alegre (RS), Brazil.

Physician, specialist in Pathology - Pathologist of the Charity Hospital of Porto Alegre (Santa Casa de Misericórdia de Porto Alegre - Porto Alegre (RS), Brazil. $\mathrm{PhD}$ in Pathology from the Federal University of Health Sciences (Universidade Federal de Ciências da Saúde de Porto Alegre - UFCSPA). Adjunct Professor of Dermatology at the Federal University of Health Sciences (Universidade Federal de Ciências da Saúde de Porto Alegre - UFCSPA) - Porto Alegre (RS), Brazil. Dermatologist and Pediatrician at the Charity Hospital of Porto Alegre (Santa Casa de Misericórdia de Porto Alegre - Porto Alegre (RS), Brazil. 


\section{CASE REPORTS}

Case 1

A female patient presented at birth with an atrophic and slightly scaly hyperpigmented patch on the face, with numerous telangiectasias. The lesion was localized in the periorbital, right temporal region and cheeks (Figure 1). The patient was born full term to a Caucasian woman, via normal spontaneous vaginal delivery. No further alterations were observed in the clinical exam.

The following exams were performed: complete blood count, urine tests, hepatic transaminases, bilirubins, urea and creatinine; all results were normal except for a thrombocytopenia (76,000 platelets). Serology for TORSCH (toxoplasmosis, rubeola, syphilis, cytomegalovirus e herpes simples virus) was nonreactive. ANA was reactive 1:650 with a fine-speckled nuclear pattern. Anti-SSA/Ro and Anti-SSB/La were not reactive, but anti-RNP was $>100 \mathrm{U} / \mathrm{mL}$ (reagent $>14$ ) and anti-Sm 8 (reagent $>7$ ). The newborn's echocardiogram and electrocardiogram were normal. The antibodies and titers present in the mother were exactly the same as those found in the newborn. At the follow-up appointment a vitamin $\mathrm{A}+\mathrm{D}$ supplement was prescribed and the mother was advised to avoid exposing the child to sunlight. After one month, the platelets were normal. All antibodies became negative at seven months. Ninety percent of the cutaneous lesions had disappeared when the child was eight months old (Figure 2).

\section{Case 2}

A 2-month old female patient had presented cutaneous lesions since she was 15 days old. The patient was born to a woman of African descent, full term, via normal spontaneous vaginal delivery. No

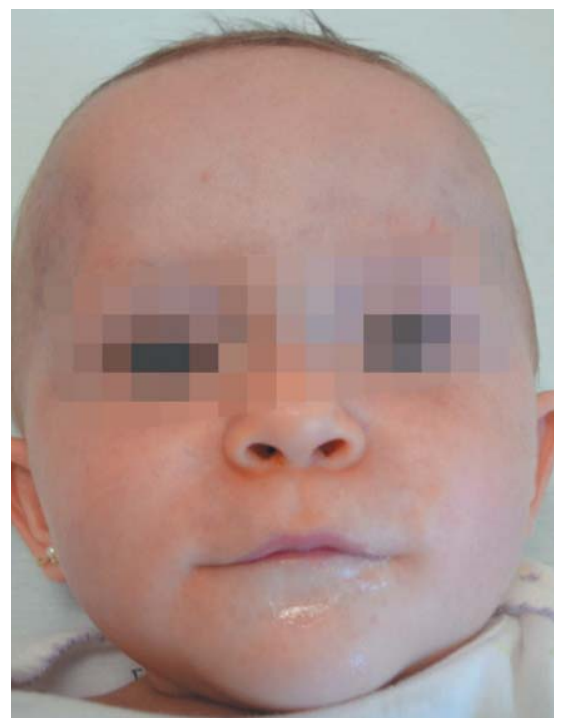

Figure 2: Patient at eight months

complications occurred during pregnancy or delivery. The infant was breastfed. At clinical examination, the patient presented erythematous eruption of annular and polycyclical patches, with slight central hypopigmentation. Lesions were observed on the face, scalp (Figure 3) and upper body. No further alterations were observed in the clinical exam.

The skin biopsy findings are shown in figure 4 . Direct immunofluorescence showed trace amounts of IgM at the dermoepidermal junction.

The following exams were performed: complete blood count, urine tests, hepatic transaminases, bilirubins, urea, creatinine, VDRL, and all results were normal. ANA was reactive 1:320 with a fine-speckled nuclear pattern. Anti-SSA/Ro and Anti-SSB/La were not reactive. The mother's laboratorial investigation showed reactive ANA (1:5120) with a fine-speckled nuclear pattern, reactive anti-SSA/Ro and anti-SSB/La.

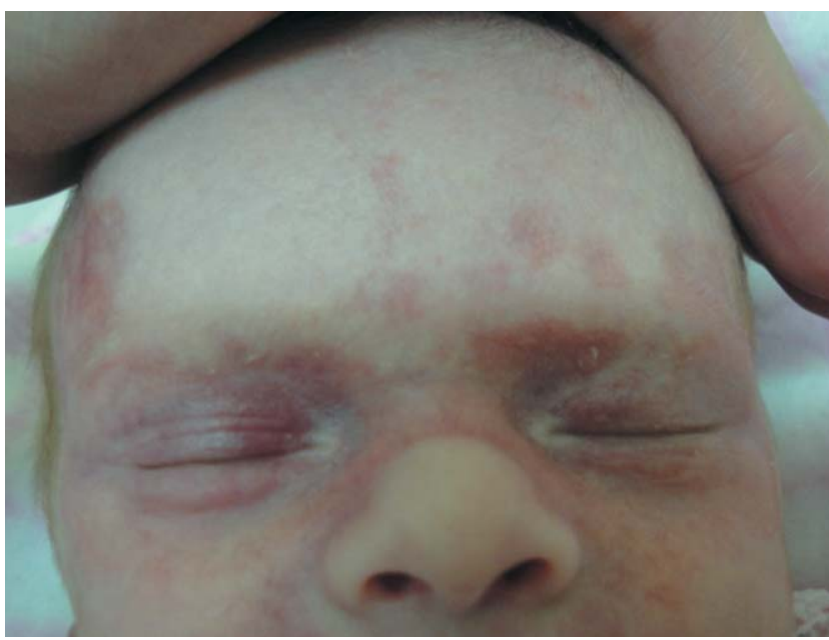

Figure 1: Periorbital atrophic lesions, telangiectasias and erythematous scaly patches

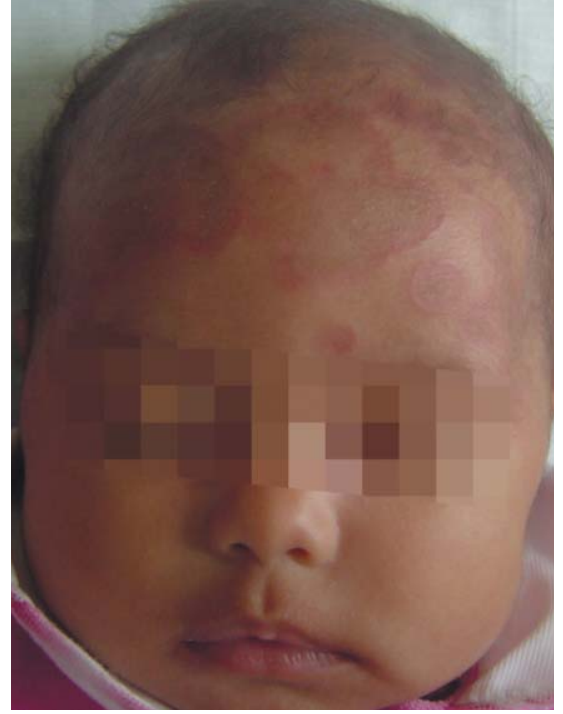

FiguRE 3:

Erythematous eruption of annular and polycyclical patches, with slight central hypopigmentation 


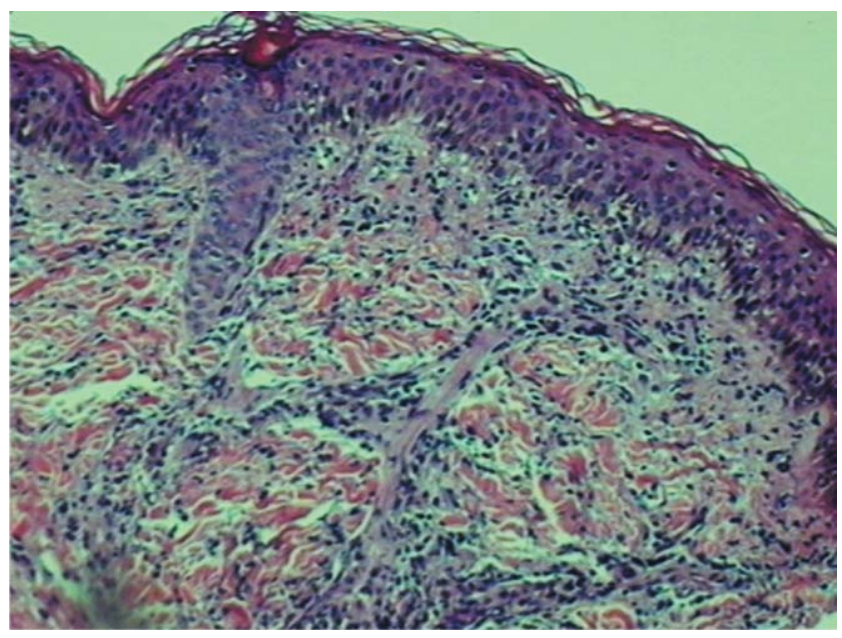

FIGURE 4: Slight epidermal atrophy, hyperkeratosis and corneal plugs. Superficial dermis demonstrated a lymphocytic inflammatory infiltrate with few histiocytes and compromised basal cells

The infant's echocardiogram and electrocardiogram were normal. At the follow-up appointment, sunscreen was prescribed. Cutaneous lesions disappeared and antibodies (ANA, Anti-SSA/Ro and Anti-SSB/La) were negative when the infant was 6 months old (Figure 5).

\section{DISCUSSION}

NLE and its congenital variant (CLE) are uncommon autoimmune diseases presenting mainly with dermatitis and congenital heart block (CHB). The infants also have, less frequently, thrombocytopenia, transient hepatic involvement, aplastic anemia and neurologic symptoms secondary to central system vasculopathy. ${ }^{2-4}$ It is a form of acquired autoimmunity in which the autoimmune process is associated with the presence of auto antibodies in the maternal-fetal circulation. It is described in neonates of mothers with positive anti-Ro (although anti-La and, less likely, antiU1-RNP may also be involved), and the precise incidence of the disease is still unknown. ${ }^{2}$ The first case, besides being congenital, is especially rare, since the anti-Ro and anti- La antibodies were negative and also presented thrombocytopenia.

About $50 \%$ of women with circulating auto antibodies who have children with NLE are asymptomatic, and some of them will develop some kind of rheumatologic disease, particularly Sjögren syndrome, systemic lupus erythematous, and less often mixed connective tissue disease. ${ }^{3}$

NLE dermatitis is a transitory benign condition, manifested by annular or polycyclic erythematous scaling rash in most of cases. Lesions commonly appear weeks after birth. Their distribution is usually on sunexposed areas, mainly the cephalic segment, inclu-

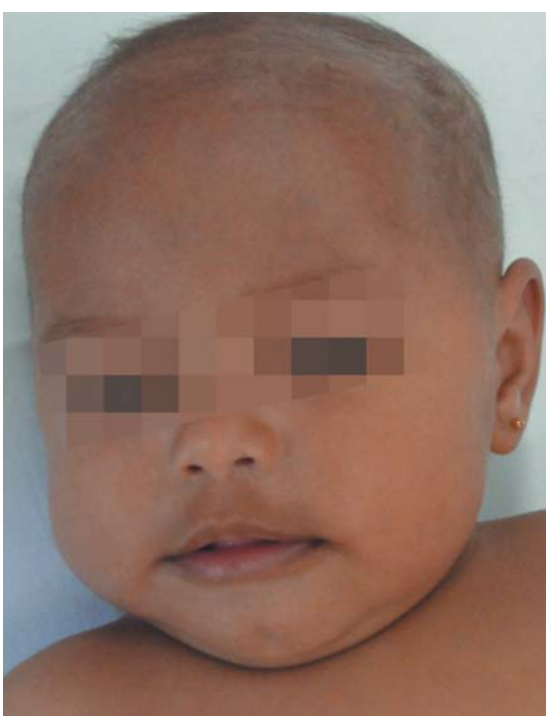

Figure 5: Regression of skin lesions at six months old ding face, scalp and neck, typically compromising the periorbital region. ${ }^{5}$ Lesions are usually transitory, with a duration of approximately seven-months, coinciding with the disappearance of IgG in maternal circulation. ${ }^{3,5}$ CLE is very unusual and cutaneous lesions can differ from NLE, presenting with atrophy or scarring. ${ }^{6}$ The cases described possessed skin lesions with typical morphology and distribution. In both cases, the antibodies and lesions disappeared within the expected time.

Dermatologic and histopathological findings correspond to subacute cutaneous lupus of the adult. ${ }^{1}$ Vacuolar degeneration of the dermoepidermal junction, perivascular lymphocytic infiltrate, moderate hyperkeratosis and follicular plugging may occur. Direct immunofluorescence shows granular deposition of IgG and, less frequently, IgM and $\mathrm{C} 3$ at the dermoepidermal junction.

NLE is the main cause of isolated CHB which typically starts during the $2^{\text {nd }}$ or $3^{\text {rd }}$ trimester of gestation, and is responsible for the high mortality (20$30 \%)$ and morbidity of these patients. ${ }^{1}$ An estimated $15-30 \%$ of patients with NLE will develop CHB, with approximately $60 \%$ of them requiring pacemaker implants. ${ }^{3}$ NLE is rare in infants with skin lesions, with only $8.7 \%$ of children manifesting both cardiac and skin involvement. ${ }^{8}$ Despite this, children suspected of NLE must be submitted to an electrocardiograph and echocardiogram. Neonates require a 6-month cardiac follow up, from the day of birth until the time when maternal antibodies disappear. If CHB occurs, its presence correlates to a higher morbimortality.' Treatment of the mother with oral corticoids, directing the treatment to the fetus with suspected $\mathrm{CHB}$, is a promising, although controversial alternative.$^{10} \mathrm{CHB}$ 
was not found in our patients.

NLE and CLE diagnosis can be confirmed through history, physical examination and the presence of specific antibodies in fetal and maternal circulation. Skin biopsy is useful, although not essential to establish diagnosis. Differential diagnosis includes perinatal infections (cytomegalovirus, group B Streptococcus and syphilis) and other non-infectious neonatal dermatitis such as drug eruptions, tinea corporis and erythema multiforme. Genetic diseases and atrophy or cutaneous aplasia should also be considered. ${ }^{2}$ Children with NLE or CLE have a slightly higher risk of developing some type of autoimmune disease in the future, but the frequency of this risk is unknown. ${ }^{10,11}$

The prognosis for children with cutaneous lesions is excellent and the majority of those lesions disappear during the first semester of life, even without treatment. Nevertheless, measures of photoprotection are recommended. ${ }^{10}$

\section{REFERENCES}

1. Diociaiuti A, Paone C, Giraldi L, Paradisi M, El Hachem M. Congenital lupus erythematosus: case report and review of the literature. Pediatr Dermatol. 2005; 22: 240-2.

2. Peñate $\mathrm{Y}$, Guillermo N, Rodríguez J, Hernández-Machín B, Montenegro T, Afonso JL, et al. Histopathological characteristics of neonatal cutaneous lupus erythematosus: description of five cases and literature review. J Cutan Pathol. 2009;36:660-7.

3. Carvalho JF, Viana VST, Cruz RBP, Bonfá E. Síndrome do lúpus neonatal. Rev. Bras. Reumatol. 2005:45:153-60.

4. Lee LA. Neonatal lupus: clinical features and management. Pediatr Drugs. 2004;6: 71-8.

5. Weston WL, Morelli JG, Lee LA.J.The clinical spectrum of anti-Ro-positive cutaneous neonatal lupus erythematosus. J Am Acad Dermatol. 1999:40:675-81.

6. Cheng CL, Galbraith S, Holland K. Congenital lupus erythematosus presenting at birth with widespread erosions, pancytopenia, and subsequent hepatobiliary disease. Pediatric Dermatol. 2010;27:109-11.

7. Boh EE. Neonatal lupus erythematosus. Clin Dermatol. 2004;22:125-8.

8. Izmirly PM, Rivera TL, Buyon JP. Neonatal lupus syndromes. Rheum Dis Clin North Am. 2007;33:267-85.

9. Press J, Uziel Y, Laxer RM, Luy L, Hamilton RM, Silverman ED. Long-term outcome of mothers of children with complete congenital heart block. Am J Med. 1996;100:328-32.
10. Lee LA. Transient autoimmunity related to maternal autoantibodies: neonatal lupus. Autoimmun Rev. 2005;4:207-13

11. Perez MF, Torres ME, Buján MM, Lanoël A, Cervini AB, Pierini AM. Neonatal lupus erythematosus: a report of four cases. An Bras Dermatol. 2011;86:347-51.

How to cite this article: Frey MN, Ioppi AEE, Garbin GC, Furian RD, Kiszewski AE. Congenital and neonatal lupus erythematosus: two case reports. An Bras Dermatol. 2012;87(4):625-8. 